\title{
Bahaya Asap dan Radiasi Sinar Las Terhadap Pekerja Las di Sektor Informal
}

\author{
Abdul Qolik ${ }^{1}$, Yoto, Basuki ${ }^{2}$, Sunomo $^{3}$, dan Wahono ${ }^{4}$ \\ 1,2,3,4 Program Studi S1 Pendidikan Teknik Mesin Jurusan Teknik Mesin \\ ${ }^{1,2,3,4}$ Fakultas Teknik Universitas Negeri Malang \\ 1,2,3,4 Jalan Semarang No. 5, Malang 65145 \\ Email: abdulqolik@gmail.com; yoto.ft@um.ac.id; basuki.ft@um.ac.id
}

\begin{abstract}
Abstrak: Proses pengelasan jika tidak diperhitungkan sebelumnya dapat mengakibatkan bahaya-bahaya yang tidak diinginkan bagi pekerja las, contohnya kebakaran, peledakan, keretakan, dan bahaya yang tidak kalah pentingnya adalah bahaya yang mengganggu alat pernapasan. Bahaya tersebut berasal dari asap dan radiasi sinar las. Meskipun demikian, pedoman untuk bekerja secara aman sesuai dengan prosedur kesehatan dan keselamatan kerja seringkali diabaikan, terutama oleh pekerja las di sektor informal dengan skala kecil. Oleh karena itu sangat wajar jika seringkali ditemukan tenaga kerja di bengkel pengelasan yang bekerja dengan tingkat keamanan yang sangat minim. Keadaan tersebut menyebabkan perlunya diadakan pelatihan guna meningkatkan pemahaman bahaya proses pengelasan serta keselamatan dan kesehatan pekerja las di sektor informal.
\end{abstract}

Kata kunci: Bahaya, asap, radiasi, pekerja las.

\begin{abstract}
If the welding process are not taken into account beforehand can lead to unwanted hazards for welding workers, for example fire, blasting, cracking, and danger which is no less important is the danger that interferes with the breathing apparatus. The danger comes from fume and welding radiation. However, guidelines for working appropriately with health and informal work, with workers in the informal sector on a small scale. Therefore it is very reasonable if there is a workforce in the workshop that works at a very minimal level. This situation is needed for training to improve the process capability and workforce in the informal.
\end{abstract}

Keywords: Hazards, fume, radiation, welding workers.

Proses kegiatan manufacturing selalu memiliki resiko/bahaya terutama bagi pekerja. Salah satunya adalah bahaya pada saat pengelasan, hal tersebut dikarenakan pekerja akan terpapar asap dan radiasi sinar las. Undang-Undang RI No. 23 tahun 1992 tentang Kesehatan, pada pasal 23 menyatakan bahwa Kesehatan kerja diselenggarakan untuk mewujudkan produktivitas kerja yang optimal. Kesehatan kerja meliputi pelayanan kesehatan kerja, pencegahan penyakit akibat kerja dan syarat kesehatan kerja. Setiap tempat kerja wajib menyelenggarakan kesehatan kerja. Ketetapan ini harus dijalankan oleh sektor formal maupun informal. Wahyuni (2013:2) menyatakan bahwa industri sektor informal dengan skala kecil, dengan permodalan kecil, dan keuntungan yang tidak terlalu besar menyebabkan pengelola usaha (baik pemilik dan pekerja) lebih berfokus pada hasil produksi yang didapatkan dibandingkan dengan perhatian pada kesehatan dan keselamatan kerja. Peralatan dan perlengkapan keselamatan yang seadanya memperbesar peluang terpapar radiasi panas ataupun kecelakaan kerja.

Menurut Fahed, dkk (2018:2) Some researchers have provided empirical proof from the manufacturing and agriculture sectors that increasing heat stress has an adverse impact on workers' productivity by reducing their working capabilities, especially in developing countries. Selain itu Krishnamurthy (2017:1) juga menyatakan bahwa heat is one of the physical hazards that can cause health problems in the workplace and one of the most important and common occupational health problems inworkplaces is inappropriate thermal conditions that can impact the health and productivities of workers. Hal tersebut membuktikan bahwa terpapar radiasi panas memiliki dampak negatif pada produktivitas pekerja yaitu mengurangi kemampuan kerja.

Pedoman untuk bekerja secara aman sesuai dengan prosedur kesehatan dan keselamatan kerja seringkali diabaikan oleh pekerja las. Hassan, dkk (2013) menyatakan bahwa tingkat kesadaran pekerja terhadap keselamatan dan kesehatan kerja merupakan aspek penting dalam pelaksanaan konstruksi agar terbentuk kondisi yang baik bagi pekerja itu sendiri. Persepsi yang tidak benar dapat meningkatkan kemungkinan seseorang berperilaku tidak aman yang dapat menyebabkan terkena penyakit akibat kerja ataupun mengakibatkan kecelakaan kerja yang dapat merugikan banyak pihak.

\section{BAHAYA ASAP PADA LAS}

Asap adalah suspensi partikel kecil di udara yang berasal dari pembakaran tak sempurna dari suatu bahan bakar. Asap umumnya merupakan produk sampingan yang tidak diinginkan. Sedangkan didalam asap pengelasan sendiri terdapat kandungan debu dan gas, kandungan inilah yang nantinya dapat menimbulkan beberapa iritasi terhadap saluran pernafasan. 
Menurut Depkes RI (2003) dalam kondisi tertentu, asap atau debu merupakan bahaya yang dapat menyebabkan pengurangan kenyamanan kerja, gangguan penglihatan, gangguan fungsi faal paru bahkan dapat menimbulkan keracunan umum.

Asap biasanya terlihat pada setiap operasi pengelasan. Asap ini terdiri dari komponen yang dihasilkan dari elektroda dan logam pada saat proses pengelasan. Menurut Sutrisno (1993) dan Alip (1989) komposisi kimia dari debu asap las tergantung dari jenis pengelasan dan elektroda yang digunakan. Dalam pengelasan baja komposisi yang utama, seperti yang terlihat dalam tabel di bawah, adalah oksida besi (Fe2O2) di tambah dengan debu lain yang tergantung dari elektrodanya. Bila digunakan elektroda jenis hedrogen rendah, di dalam debu asap akan terdapat fluor (F) dan oksida kalium (K2O). Dalam pengelasan busur listrik tanpa gas, asapnya akan banyak mengandung oksida magnesium (MgO).

Menurut Ramli (2013) Debu dalam asap las apabila terisap akan tertahan oleh bulu hidung atau bulu pipa pernapasan, sedangkan yang lebih halus akan terbawa masuk ke dalam paru-paru, dan sebagian akan dihembuskan keluar kembali. Debu asap yang tertinggal dan melekat pada kantong udara di paru-paru dapat menimbulkan beberapa penyakit, seperti sesak nafas dan lain sebagainya. Sedangkan Gas-gas berbahaya yang terjadi pada waktu pengelasan adalah gas karbon monoksida (CO), karbon dioksida (CO2), ozon (O3), dan gas nitrogendioksida (NO2), serta jenis gas beracun lainnya akibat pengurain dari bahan pembersih dan pelindung terhadap karat.

Daryanto (2013:143) berpendapat bahwa penguapan logam peleburan terjadi dari ujung batang elektrode las atau kawat las, tetesan-tetesan kecil yang berpindah dan permukaan genangan yang meleleh, sehingga uap air logam bertemperatur tinggi disemburkan ke sekeliling titik pengelasan. Uap air itu cepat menjadi dingin dan melebur didalam partikel-partikel kecil berdiameter 0,1-10 $\mu \mathrm{m}$. Meskipun kelihatannya seperti asap biasa, asap gas las ini sebenarnnya mengandung partikel-partikel murni. Ukuran partikel-partikel ini memungkinkan untuk mudah masuk ke dalam paru-paru.

\section{BAHAYA RADIASI SINAR LAS}

National Safety Counci (2002) menyatakan bahwa potensi bahaya pengelasan yang dapat ditimbulkan dari proses pengelasan yaitu radiasi sinar las. Selama proses pengelasan akan menimbulkan cahaya dan sinar yang dapat membahayakan juru las dan pekerja lain yang ada di sekitar pengelasan. Cahaya tersebut meliputi cahaya yang dapat dilihat atau cahaya tampak, sinar ultraviolet dan sinar infra merah.

Penelitian di Amerika tahun 1987 tentang "Evaluasi bahaya potensial dari radiasi optic pada pengelasan listrik" menyatakan bahwa tipe elektroda berdasarkan perbedaan diameter dan tingkat ampere elektroda mempengaruhi tingkat keparahan kerusakan pada mata pekerja las listrik. Pengelasan listrik diketahui memiiki potensi bahaya radiasi sinar ultraviolet terbesar dari elektrodanya bila dibandingkan dengan pengelasan dengan gas asetilen (Patty, 1991).

Menurut Sumanto (1991:3) radiasi merupakan bagian dari jagat raya jauh sebelum terjadinya kehidupan dimuka bumi. Material radioaktif juga bagian dari formasi bumi, termasuk manusia sendiri dalam bagian yang amat kecil mengandung komponen radioaktif dalam substansi jaringan tubuhnya. Namun fenomena radiasi dan radioaktifitas baru dikenal manusia sejak pengamatan Henri Becquerel, Marie Curie, serta Wilhelm Conrad Roentgen, sedangkan efek merusak jaringan hidup oleh radiasi pertama kali dikenal saat Henri Becquerel mengantungi radium dalam vial dan kemudian menyebabkan timbulnya kerusakan pada kulit. Sedangkan menurut Utomo (1999:8) radiasi merupakan transfer panas dalam bentuk gelombang elektromagnetik tanpa atau menggunakan medium oleh benda padat, cair atau gas.

Secara garis besar radiasi digolongkan ke dalam radiasi pengion atau radiasi ionisasi dan radiasi non-pengion atau radiasi non-ionisasi. Menurut Ridley (2008:134) radiasi dari peluruhan radioaktif menyebabkan material yang dilewatinya mengalami ionisasi. Peristiwa ini dikenal dengan istilah 'radiasi ionisasi'. Pengaruhnya terhadap jaringan tubuh bergantung pada sifat alami atau jenis radiasi, dosis dan lamanya eksposur, apakah sumbernya merupakan bagian internal atau eksternal tubuh. Jenis radiasi ionisasi yaitu partikel $\alpha$ (alfa), partikel $\beta$ (beta), sinar $\gamma$ (gama), sinar X, dan partikel neutron.

Sumber radiasi yang dapat mempengaruhi manusia di kelompokkan menjadi 2, yaitu sumber radiasi alami dan sumber radiasi buatan, radiasi alami yang terjadi dalam bentuk sinar kosmik yang berasal dari luar angkasan dan radioaktif dari kerak bumi sedangkan radiasi buatan berasal dari tindakan medis, ledakan nuklir, pembangkit tenaga nuklir dan paparan pada pekerja seperti yang terjadi pada proses pengelasan. Berikut adalah gambar sumber radiasi alami dan sumber radiasi buatan (Yatiman, 1991; Wiryosimin, 1995)

\section{TENAGA KERJA DAN PERLINDUNGAN TENAGA KERJA}

Menurut Undang-Undang Ketenagakerjaan No.13 Tahun 2003 Pasal 1, ketenagakerjaan adalah segala hal yang berhubungan dengan tenaga kerja pada waktu sebelum, selama dan sesudah masa kerja. Tenaga kerja adalah setiap orang yang mampu melakukan pekerjaan guna menghasilkan barang atau jasa baik untuk memenuhi kebutuhan sendiri maupun untuk masyarakat.

Sedangkan Menurut Simanjuntak (1985:2) tenaga kerja mencakup penduduk yang sudah bekerja atau sedang bekerja, yang sedang mencari pekerjaan, dan yang melakukan kegiatan lain seperti bersekolah dan mengurus rumah tangga. Secara praktis pengertian tenaga kerja dan bukan tenaga kerja dibedakan hanya oleh batas umur dimana setiap negara memberikan batas umur yang berbeda. Tujuan dari pemilihan batas umur tersebut supaya definisi yang diberikan sedapat mungkin 
menggambarkan kenyataan yang sebenarnya bahwa tiap negara memiliki memiliki batas umur yang berbeda karena situasi tenaga kerja dimasing-masing negara juga berbeda.

Pada saat ini, diberbagai negara dibelahan dunia telah mengupayakan perlindungan keselamatan dan kesehatan kerja dengan mengeluarkan peraturan perundang-undangan untuk melindungi keselamatan tenaga kerja. Di Indonesia dikeluarkan Undang-Undang No.1 Tahun 1970 tentang Keselamatan Kerja dan Undang-Undang No. 13 Tahun 2003 tentang Ketenagakerjaan. Setiap organisasi wajib menerapkan upaya keselamatan dan kesehatan kerja untuk melindungi keselamatan tenaga kerja. Mewajibkan setiap organisasi melaksanakan sistem manajemen keselamatan dan kesehatan kerja (K3) yang terintegrasi dengan manajemen organisasi lainnya (UU No.13/2003 Pasal 86 dan 87).

Pekerjaan di bengkel las jika tidak diperhitungkan sebelumnya dapat mengakibatkan bahaya-bahaya yang tidak diinginkan. Selain itu cara berfikir juga mempengaruhi pekerja dalam memperhatikan kesehatan. Pekerja di sektor informal di skala kecil rata-rata memiliki pola pemikiran bahwa selama pekerja tidak terganggu, keluhan kesehatan akan dianggap lumrah atau biasa sehingga pekerja tidak akan membutuhkan pelayanan kesehatan apabila gangguan kesehatan yang dirasakan belum benar-benar parah. (Wahyuni, 2013). Oleh karenanya pemahaman terhadap bahaya radiasi sinar las dan asap akibat las harus dicegah dengan sebaik-baiknya. Pencegahan dilakukan dengan cara: (1) kesadaran pekerja las untuk menggunakan alat pelindung diri pada saat mereka melakukan pekerjaan las, (2) melaksanakan pekerjaan las yang aman dan nyaman agar terhindar dari bahaya radiasi dan bahaya asap akibat pekerjaan las, dan (3) tersedianya alat pelindung diri yang sesuai dengan yang dibutuhkan dilapangan.

\section{ALAT PELINDUNG DIRI}

OSHA (2007) menyatakan bahwa alat pelindung diri (APD) atau personal protective equipment (PPE) didefinisikan sebagai alat yang digunakan untuk melindungi pekerja dari luka atau penyakit yang diakibatkan oleh adanya kontak dengan bahaya (hazards) di tempat kerja, baik yang bersifat kimia, biologis, radiasi, fisik, elektrik, mekanik dan lainnya. Sedangkan menurut Tarwaka (2008), alat pelindung diri merupakanseperangkat alat keselamatan yang digunakan oleh pekerja untuk melindungi seluruh atau sebagian tubuhnya dari kemungkinan adanya pemaparan potensi bahaya lingkungan kerja terhadap kecelakaan dan penyakit akibat kerja.

Oleh karena itu penggunaan APD merupakan hal yang sangat penting karena dapat mencegah timbulnya kecelakaan akibat suatu pekerjaan dan penyakit akibat kerja. Pekerja yang tidak menggunakan masker atau alat pelindung diri pernafasan yang sesuai dengan standar akan memperbesar risiko untuk terjadinya gangguan fungsi paru (Rikmiarif, 2012).

Sari (2014) menyebutkan bahwa penggunaan APD yang baik akan memberikan perlindungan bagi pekerja dari kejadian tidak terduga atau dari keparahan dampak kecelakaan kerja sehingga dapat meningkatkan produktivitas baik pekerja maupun perusahaan. Namun pada kenyataannya, banyak pekerja yang masih mengabaikan peraturan penggunaan APD yang berlaku karena berbagai alasan, sehingga kemungkinan untuk terjadi kecelakaan akan lebih besar.

Harry dalam Amin (1985) menyatakan pemakaian APD sangat penting sebagai garis pertahanan untuk melindungi pemakai sebagai akibat dari kelalaian atau kondisi yang tidak diperkirakan. Alat pelindung diri adalah seperangkat alat yang digunakan tenaga kerja untuk melindungi sebagian atau seluruh tubuhnya dari adanya potensi bahaya atau kecelakaan. Alat ini digunakan seseorang dalam melakukan pekerjaannya, yang dimaksud untuk melindungi dirinya dari sumber bahaya tertentu baik yang berasal dari pekerjaan maupun dari lingkungan kerja. Alat pelindung diri ini tidaklah secara sempurna dapat melindungi tubuhnya tetapi akan dapat mengurangi tingkat keparahan yang mungkin terjadi (Budiono, 2003).

\section{KESIMPULAN}

Selama proses pengelasan dilakukan akan menimbulkan cahaya dan sinar yang dapat membahayakan juru las dan pekerja lain yang ada di sekitar pengelasan. Cahaya tersebut meliputi cahaya yang dapat dilihat atau cahaya tampak, sinar ultraviolet dan sinar infra merah. Akibat yang dialami karena kurangnya pemahaman pekerja las terhadap perlindungan asap dan radiasi sinar las terhadap tubuh dan pekerja yang tidak menggunakan APD sesuai standard yaitu tubuh pekerja las akan terpapar radiasi sinar las. Selain itu banyaknya pekerja las yang kurang paham terhadap penggunaan alat pelindung diri guna meningkatkan produktifitas, kualitas kerja, dan keamanan kerja. Sedangkan pemakaian perlengkapan K3/APD sangat penting yaitu sebagai garis pertahanan untuk melindungi pemakai dari kelalaian atau kondisi yang tidak diperkirakan.

\section{SARAN}

Bagi Industri atau bengkel las perlu mengadakan kegiatan pelatihan keselamatan dan kesehatan kerja bagi pekerja las, guna meningkatkan pemahaman pekerja mengenai pentingnya tingkat kesadaran pekerja terhadap keselamatan dan kesehatan kerja. Hal tersebut bertujuan untuk mengurangi kecelakaan yang dapat memberikan dampak negatif terhadap pekerja dan pelaksanaan suatu proyek, seperti kerugian materi dan moril, keterlambatan penyelesaian proyek, kehilangan jam kerja, mengakibatkan kecacatan, bahkan dapat menghilangkan nyawa. Dengan adanya pelatihan akan menghasilkan suatu perubahan pada pekerja. Pelatihan yang diberikan khusus terkait keselamatan dan kesehatan kerja serta penggunaan APD yang sesuai 
standar bertujuan agar pengetahuan pekerja terkait keselamatan dan kesehatan kerja serta APD bertambah dan menumbuhkan pola pikir betapa pentingnya menggunakan APD saat bekerja.

\section{DAFTAR RUJUKAN}

Alip, M. 1989. Teori dan Praktek Las. Jakarta: Departemen Pendidikan dan Kebudayaan Direktort Jendral Pendidikan Tinggi Proyek Pengembangan Lembaga Pendidikan Tenaga kependidikan.

Amin, M. 1985. Pengaruh Polusi Udara Terhadap Fungsi Paru. Surabaya: Pulmonologi Fakultas Kedokteran Unair, RS Dr sutomo.

Budiono., dkk. 2003. Bunga Rampai HIPERKES \& KK: Higiene Perusahaan, Ergonomi, Kesehatan Kerja, Keselamatan Kerja. Semarang: Badan Penerbit UNDIP.

Daryanto. 2013. Teknik Las. Bandung: Alfabeta.

Depkes RI. 2003. Keputusan Menteri Kesehatan RI dan Keputusan Dirjen PPM\&PLP tentang Persyaratan Kesehatan Lingkungan Kerja. Jakarta: Depkes RI.

Fahed, Abdel., Ozkaymak Mehmet., Ahmed Siraj. 2018. Impacts of heat exposure on workers' health and performance at steel plant in Turkey. Turkey: Engineering Science and Technology an International Journal. 21 (2018) 745-752.

Hassan, C. R. C., dkk. 2013. Perception of Building Construction Workers Towards Safety, Health And Environment. Malaysia: Journal of Engineering Science and Technology.

Krishnamurthy, M., Ramalingam, P., Perumal, K., Kamalakannan, L., Chinnadurai, J., Shanmugam, R., Srinivasan, K., Venugopal, V. Occupational Heat Stress Impacts on Health and Productivity in a Steel Industry in Southern India. 2017. India: Occupational Safety and Health Research Journal. 8 (2017) 99-104.

National Safety Council. 2002. Risk Perception: Theories, Strategies And Next Steps. Amerika: Campbell Institute National Safety Council.

Occupational Safety and Health Administration (OSHA). 2007. Personal Protective Equipment (PPE). U.S: U.S. Department of Labor.

Patty, F.A. 1991. Industrial Hygiene and Toxicologi $4^{\text {th }}$ ed. New York: John Wiley and Sons.

Ramli, S. 2013. Sistem Manajemen Keselamatan \& Kesehatan Kerja Ohsas 18001 (H. Djajaningrat, Ed.). Jakarta: Dian Rakyat.

Ridley, J. 2008. Ikhtisar Kesehatan dan Keselamatan Kerja. Jakarta: Erlangga.

Rikmiarif, D. 2012. Hubungan Pemakaian Alat Pelindung Pernapasan Dengan Tingkat Kapasitas Vital Paru. Unnes Journal of Public Health, (Online), Vol. 1, No. 1, Agustus 2012, Hal 12-17, (http://journal. unnes.ac.id/sju/index.php/ujph/article/do wnload/175/183). Diakses pada tanggal 29 Juli 2018.

Sari, R. E. (2014). Kepatuhan Peraturan Keselamatan Kerja Sebagai Mediator Pengaruh Iklim Keselamatan Kerja terhadap Kecenderungan Mengalami Kecelakaan Kerja.Yogyakarta: Jurnal Psikologi MANDIRI.

Simanjuntak. 1985. Pengantar Ekonomi Sumber Daya Manusia. Jakarta: Fakultas Ekonomi Universitas Indonesia.

Sumanto. 1991. Bahaya Radiasi Bagi Manusia. Jakarta: Badan Tenaga Atom Nasional.

Sutrisno. 1983. Fisika Modern. Bandung: Institut Teknologi Bandung.

Tarwaka. 2008. Keselamatan dan Kesehatan Kerja: Manajemen dan Implementasi K3 di Tempat Kerja. Surakarta : Harapan Press.

Undang-undang Republik Indonesia Nomor 1 Tahun 1970, Tentang Keselamatan Kerja. Kementrian Tenaga Kerja dan Transmigrasi (Online), (http://www.jdih.depnakertrans.go.id), diakses 5 Maret 2015.

Undang-undang Republik Indonesia Nomor 13 Tahun 2003, Tentang Ketenagakerjaan. Kementrian Tenaga Kerja dan Transmigrasi. (Online), (http://www.ppa-feui.com), diakses 25 September 2014.

Undang-undang Republik Indonesia Nomor 23 Tahun 1992, Tentang Kesehatan. Kementrian Tenaga Kerja dan Transmigrasi.

Utomo, D.H. 1999. Meteorologi Klimatologi. Malang: Fakultas MIPA Universitas Negeri Malang Departemen Pendidikan dan Kebudayaan.

Wahyuni, Tri. 2013. Faktor Risiko yang Berhubungan dengan Kejadian Konjungtivitis pada Pekerja Pengelasan di Kecamatan Cilacap Tengah Kabupaten Cilacap. UNDIP Jurnal Kesehatan Masyarakat. Vol. 2, No. 1, 2013.

Yatiman, S. 1991. Fisika Radiasi. Jakarta: Badan Tenaga Atom Nasional. 